\title{
Revista de Investigación
}
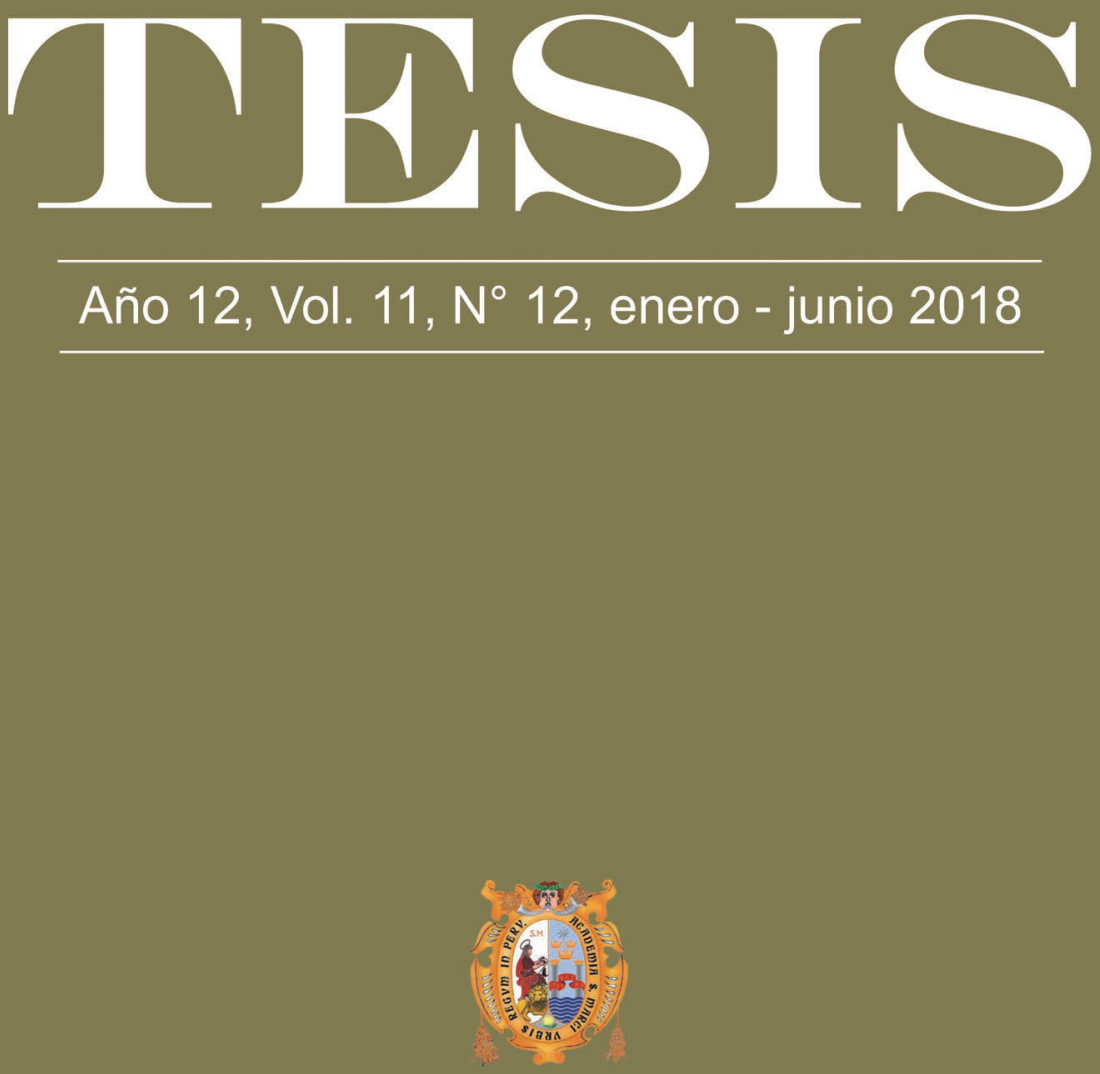

Unidad de Posgrado

Facultad de Letras y Ciencias Humanas Universidad Nacional Mayor de San Marcos 



\section{TESIS}

Revista de Investigación de la Unidad de Posgrado de la Facultad de Letras y Ciencias Humanas de la Universidad Nacional Mayor de San Marcos

Año 12, Vol. 11, No 12, enero-junio 2018

Revista semestral

ISSN 1995-6967 


\section{Tesis \\ Revista de Investigación de la Unidad de Posgrado de la Facultad de Letras y Ciencias Humanas de laUNMSM}

Tesis. Año 12, Vol. 11, No 12, enero-junio 2018

\section{Periodicidad semestral Lima, Perú}

DECANO

Mg. José Carlos Ballón Vargas

\section{Director de la Unidad de Posgrado}

Dr. Gonzalo Espino Relucé

Director de la Revista

Dr. Mauro Mamani Macedo

\section{Comité Editorial}

Dra. Nanda Leonardini Herane, Mg. Norma Isabel Meneses Tutaya, Dr. Richard Orozco

Contreras, Mg. Desiderio Evangelista, Dr. Manuel Conde Marcos. Mg. Luz Carrillo Mauriz.

\section{Comité Consultor y Evaluador}

Dr. Félix Quesada Castillo (UNMSM), Dr. Carlos García-Bedoya (UNMSM), Dr. Raimundo Prado Redondez (UNMSM), Dr. Fermín del Pino (CSIC, España), Dr. Raúl Bueno (Dartmouth College), Dr. Rómulo Montealto (UFMG), Dra. María Claudia Rodríguez (UACH), Dr. Carlos Huamán López (UNAM), Dra. Aymará de Llano (Universidad de Mar del Plata), Dr. Martín Alonso Estrada Cuzcano (UNMSM), Dr. Heinrich Helberg Chávez (UNMSM).

\section{Secretario Académico}

Dr. Mauro Mamani Macedo

\section{Editor académico}

Jacobo Alva Mendo

\section{Secretarias Administrativas}

Mirtha del Rosario Cubillas M.

Clotilde Cecilia Montejo Ugaz

Correspondencia y canje

Unidad de Posgrado-Facultad de Letras y Ciencias Humanas

Av. Venezuela 3400 *Ciudad Universitaria *Pabellón de la Facultad de Letras y Ciencias Humanas

Teléfono : (51 1) 452-1166

Correos electrónicos: upglet@unmsm.edu.pe / revistatesis.flch@unmsm.edu.pe

ISSN: 1995-6967

Depósito Legal: 2007-08404

Título clave: Tesis

Título clave abreviado: Tesis

El contenido de cada artículo es de responsabilidad exclusiva del autor y no compromete la opinión de la revista 


\section{Tesis}

Tesis. Año 12, Vol. 11, No12, enero-junio 2018

\section{Contenido}

Presentación

Mauro Mamani Macedo

\section{Estudios}

Una aproximación a la música andina: el huaino, el harawi y el yaraví

Ynés Victoria Alcántara Silva

La otredad existencial en la cuentística de Julio Ramón Ribeyro

Ronald Antenor Espinoza Aguilar

La estructura de tramas paralelas y el nacimiento del cine

Diego Alonso Sarmiento Herencia

$\mathrm{El}$ arte de escribir, el yo poético y las instancias creativas

Carla Vanessa Gonzáles Márquez

Los felices años veinte de Felipe. Fox-trot, traducción

y creación en la obra de Felipe Pinglo Alva

Rodrigo Sarmiento Herencia

Poética del cuento moderno de Flores nocturnas de Miguel Bances

Miguel Luis Bances Gandarillas

Fragmentación, vida y humor en Disonante 
Eros y Tanatos: representación de la melancolía en Ophelia

Erika Rodríguez Vásquez

Los personajes en la novela Dios no quiere pobres

Alberto Lázaro Pumalaza Díaz

Asedios a la poética de autor

Miguel Ángel Malpartida Quispe

La música como parte de la construcción ficcional

181 en Aqui está la música

Ilmar Piero Montaldo Acosta

\section{Creación}

(Poesía)

\section{Ana Luisa Ríos}

Playa Tibi

197

Maderero ausente

198

Chachamamu

199

Sabio Waimaku

200

Yacimiento

201

Lagarto negro

202

Carla Vanessa

203

Sueño de Lázaro 203

Reflexión 204

Toño 205

Carta de un indio soldado a su familia 206

$\begin{array}{ll}\text { Requisitos revista Tesis } & 207\end{array}$ 


\section{Presentación}

En esta edición, el Comité Editorial, con la aceptación de los árbitros que evalúan los artículos, ha considerado publicar once trabajos de investigación de la maestría; principalmente de la maestría en escritura creativa: trabajos donde se puede observar cómo los autores reflexionan sobre su propio proceso de creación.

La investigadora Ynés Victoria Alcántara Silva, presenta un trabajo donde formula una aproximación a la música andina y estudia el especial significado que la música tiene para los pueblos del Ande peruano. El artículo analiza el origen y evolución de los géneros musicales en el mundo andino, cuyos antecedentes se encuentran en la música prehispánica. Igualmente, el trabajo estudia el surgimiento, desarrollo y los temas de tres conocidos géneros de la música andina: el huaino, el harawi y el yaraví. De los tres géneros musicales, el huaino es el género más popular de la música andina, presenta variadas formas y se cultiva en todas las regiones del Perú. El harawi es un género de la música prehispánica que se ha conservado con determinadas características en los pueblos del interior del país. El yaraví es un género musical de carácter mestizo que surge a partir de la evolución que experimenta el harawi durante la época republicana y se caracteriza por expresar la tristeza del alma humana.

Uno de los narradores que más se ha investigado es Julio Ramón Ribeyro, en esta ocasión, Ronald Antenor Espinoza Aguilar, considera que la crítica influenciada por la filosofía marxista y otras tendencias filosóficas ha direccionado el estudio de la narrativa corta ribeyriana hacia aspectos como la marginalidad y el escepticismo. Podría decirse que una obra, aparentemente simple y sencilla como la narrativa corta de Julio Ramón Ribeyro contiene en realidad un universo ficcional complejo que no puede ser abordado desde una sola mirada, pues eso nos conduciría solo a ver en los personajes ribeyrianos calcos 
y copias de clases sociales explotadas o seres grotescos e ilusos dentro de un sistema social injusto. En discordancia con las perspectivas anteriores, el investigador plantea que, si bien el problema de la mímesis está profundamente enraizado en la cuentística ribeyriana y se hace visible a la distancia, no son en su mayoría los problemas sociales o los problemas cognoscitivos los que angustian a sus personajes, sino los problemas existenciales.

Diego Sarmiento Herencia nos explica que el cine es un fenómeno con muchas aristas y, por ello, muy difícil de explicar. Los procesos involucrados, los distintos elementos que juegan papeles importantes en el desarrollo de historias - personajes, imágenes, sonidos, etc.- son tantos y tan variados que pretender explicarlos o definirlos sería una tarea ociosa. Sin embargo, al analizar la obra de un individuo, se obtienen luces sobre su manera de fabricar, su artesanía, y así logramos encontrar un lugar común y la posible teorización de un proceso. Este artículo apunta a descubrir las relaciones entre cine y literatu$\mathrm{ra}$, desde un punto de vista estructural, utilizando la historia para determinar un lugar común y nacimiento de las técnicas que conforman el cine moderno.

Por su parte Carla Vanessa Gonzáles Márquez indaga sobre la función del yo poético en la ficción lírica; en este sentido, su trabajo busca determinar la naturaleza de la escritura creativa y qué procesos se cumplen desde el momento en que el escritor ejecuta la labor de construir los universos de ficción que constituyen una obra literaria, ya sea un cuento, una novela o un poema. Asimismo, busca definir la existencia de un yo poético como sujeto discursivo en el universo de la ficción lírica.

La música es otro de los géneros que también se estudia. Así, en el artículo "Los felices años veinte de Felipe. Fox-trot, traducción y creación en la obra de Felipe Pinglo Alva" Rodrigo Sarmiento Herencia, problematiza que hace más de 80 años que uno de los valses más conocidos y queridos del cancionero criollo peruano viene siendo interpretado de manera equivocada debido a una temprana confusión que el tiempo y la tradición terminaron por canonizar. La reciente aparición de una partitura de la canción de Felipe Pinglo publicada cuando este aún vivía, así como las declaraciones de un respetado compositor popular sobre el emblemático vals de Pinglo, dan pie al siguiente artículo que examina las tres versiones en un intento por recuperar la melodía original de "E1 Plebeyo".

A partir de su obra, Miguel Luis Bances Gandarillas, reflexiona sobra su obra. En este sentido, en su artículo busca establecer la poética del libro de cuentos Flores nocturnas de Miguel Bances. Se parte de la idea de que el ejercicio intelectual que supone la reflexión de la obra por parte del propio autor debe alejarse de ideas generales y se debe, más bien, complejizar las nociones de 
relato, personaje y lenguaje. En primer lugar, se propone la reflexión sobre dos paradigmas del cuento moderno (Poe y Chéjov) con el propósito de establecer vínculos con el género del relato. En segundo lugar, se busca la adscripción de los relatos de Flores nocturnas con el cuento epifánico. En tercer lugar, se plantea que el personaje debe ser estudiado en la dimensión crítica que propone la relación sujeto-modernidad. Finalmente, se discute la visión de la realidad a partir de la noción de lenguaje con que opera Flores nocturnas.

Miguel Lescano Tena estudia la relación que existe entre textos e imagen. El libro Disonante muestra que texto e imagen tienen la misma importancia en el lenguaje comunicativo. La relación entre ambos pone en relación ideas fragmentadas y contrastes entre poética y poética. Disonante muestra un mundo hermético donde el yo esboza una mirada irónica sobre la sociedad. Su objetivo es conseguir un acercamiento performativo entre vida y el arte. Se aspira a que el receptor extienda su imaginación hacia nuevos mundos, sin salir de esta realidad de sueños y pesadillas configuradas en blanco y negro.

Erika Rodríguez Vásquez estudia la presencia de eros y tanatos en su obra Ophelia; para ello indaga la forma en que se representa la melancolía, como resultado de la tensión entre lo erótico y lo mórbido en el poemario Ophelia. Este predominante sentimiento melancólico en los versos que constituyen el libro se analizará a partir de la correspondencia entre dos ejes: el eros y el tanatos, como fundamentos en la percepción de un tono catastrófico y el carácter mítico del personaje ofeliano. En ese sentido, se pondrá énfasis en evidenciar la presencia de un discurso y tono en el marco de creación de fin de siglo.

"Asedios a la poética de autor" de Miguel Ángel Malpartida Quispe aborda aspectos que se exponen en el marco teórico de la tesis titulada La poética específica infantil de Veloz Niño del Cielo, Veloz Niña del Alba, trabajo presentado para optar el grado de magíster en Escritura Creativa. En el texto, se plantea como objetivo la definición del concepto "poética" a partir de las acepciones que adopta en los estudios literarios (teórica, preceptiva y creativa), hasta arribar al sentido integral que se le atribuirá en la tesis: el develamiento del proceso creativo del autor a partir de una reconstrucción crítica de aquel por parte de un interpretante y/o enmarcada en la voz propia del creador. Para precisar este concepto, se analiza previamente las convergencias entre la poética, entendida como una actividad, y dos tamices de sentido: la estética posvanguardista y la lírica moderna.

Finalmente, Alberto Lázaro Pumalaza Díaz, en su obra, identifica el sufrimiento, la indiferencia, la injusticia y la corrupción en la que se encuentran involucrados los personajes. Se trata de un estudio donde abordamos la discusión de la narrativa, la ficción y de cómo crear personajes. 
Varios son los temas se presenta en este número: la música andina, la música criolla, el cine, la poesía, la narración, pero también se reflexiona sobra la escritura de autores canónicos como Julio Ramón Ribeyro. No obstante, lo más resaltante de este número es la reflexión de los autores sobre su propia obra.

Mauro Mamani Macedo 